\title{
Legal Liability of Saving Seeds in an Era of Expiring Patents
}

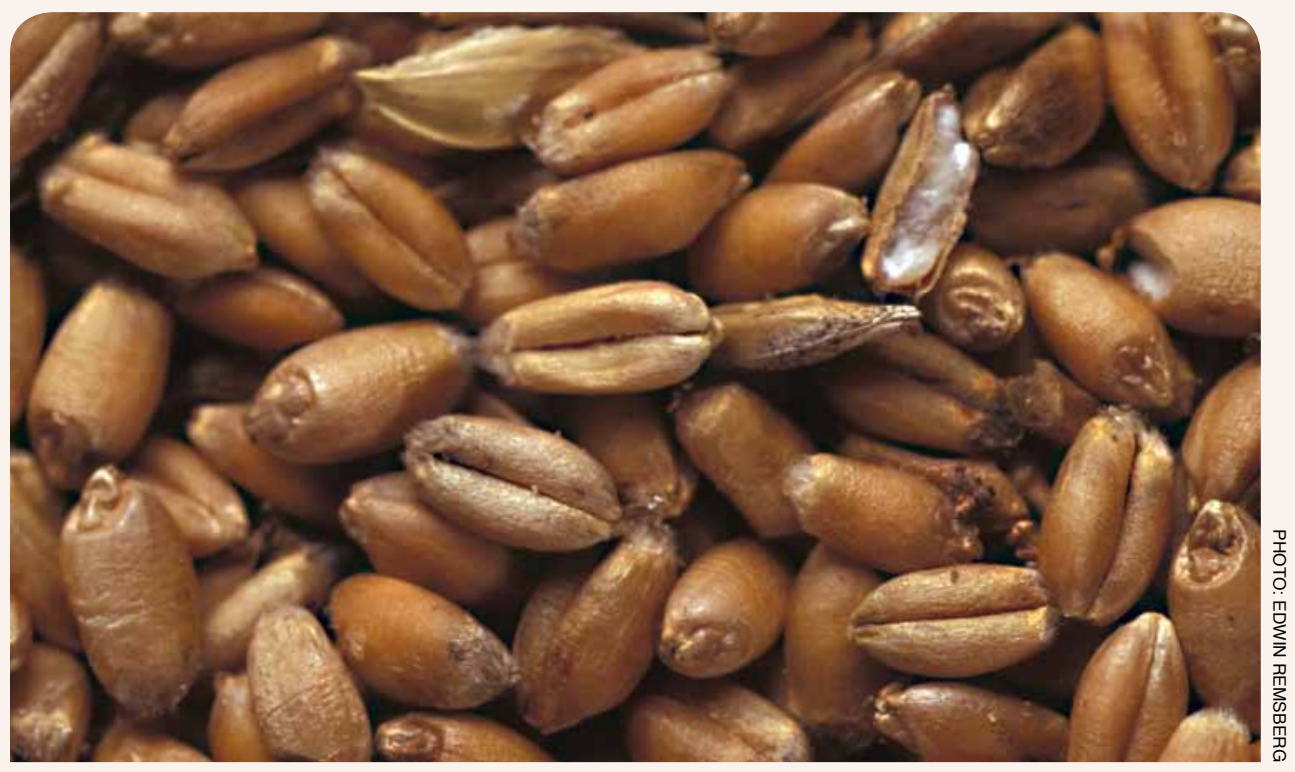

$\mathrm{M}$ onsanto's patent on the first generation Roundup Ready(C-technology expired in 2014, ending many of the protections Monsanto had under patent law.

However, patent expiration does not mean that farmers will be able to save harvested seed from first-generation Roundup Ready technology for planting subsequent crops.

Many seed companies using

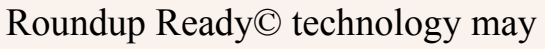
consider other federal legal protections, such as contracts and provisions of the Plant Variety Protection Act (PVPA) to restrict producers from saving seed. Seed companies also may utilize federal and state patent laws to limit seed saving.

While the Roundup Ready patent has expired, producers nonetheless need to understand the implications for their operations and how other laws may continue to limit their ability to save harvested seed for planting the following season. To determine if seed can be saved, producers should:

1) Review any agreements signed when purchasing the seed;

2) Check the label to determine if the variety is protected by the PVPA, patent law, or is unprotected; and

3) Check with the seed company.

Following these simple steps can serve as a strategy to manage the legal risks associated with seed saving.

\section{Purchase Contracts Can Limit a Farmer's Right to Save Seed}

The terms of any seed purchase contract may not only limit the right to save seed, but also the potential 
ways to market the seed. For example, a purchase contract may contain language such as, "seed produced from this crop may be saved for any purposes other than reproductive purposes ..." This or similar language would prohibit a producer from using the saved seed to plant next year's crop. The contract language, however, would allow a producer to save seed for other marketing purposes, such as holding the crop until it is sold to the local elevator.

\section{The terms of any seed} purchase contract may not only limit the right to save seed, but also the potential ways to market the seed.

Seed contracts that limit the right to save seed may contain a "damage clause" that specifies the amount of compensation a party could expect if the contract is breached. Producers should be aware of the amount of potential damages the seed company could claim. For example, a damage clause may require the breaching party (producer) to pay the nonbreaching party's (seed company) attorneys' fees and court costs. The clause may also set damages at the value of the seed purchased or at two or three times the value of the seed purchased.

Before purchasing seed, you should review the terms of any contract. Be sure you understand not only the contract's limitations on seed saving but also the content of the damages clause. Although you may be allowed to save seed under the PVPA, a contract could limit this right. If it does, a producer has no

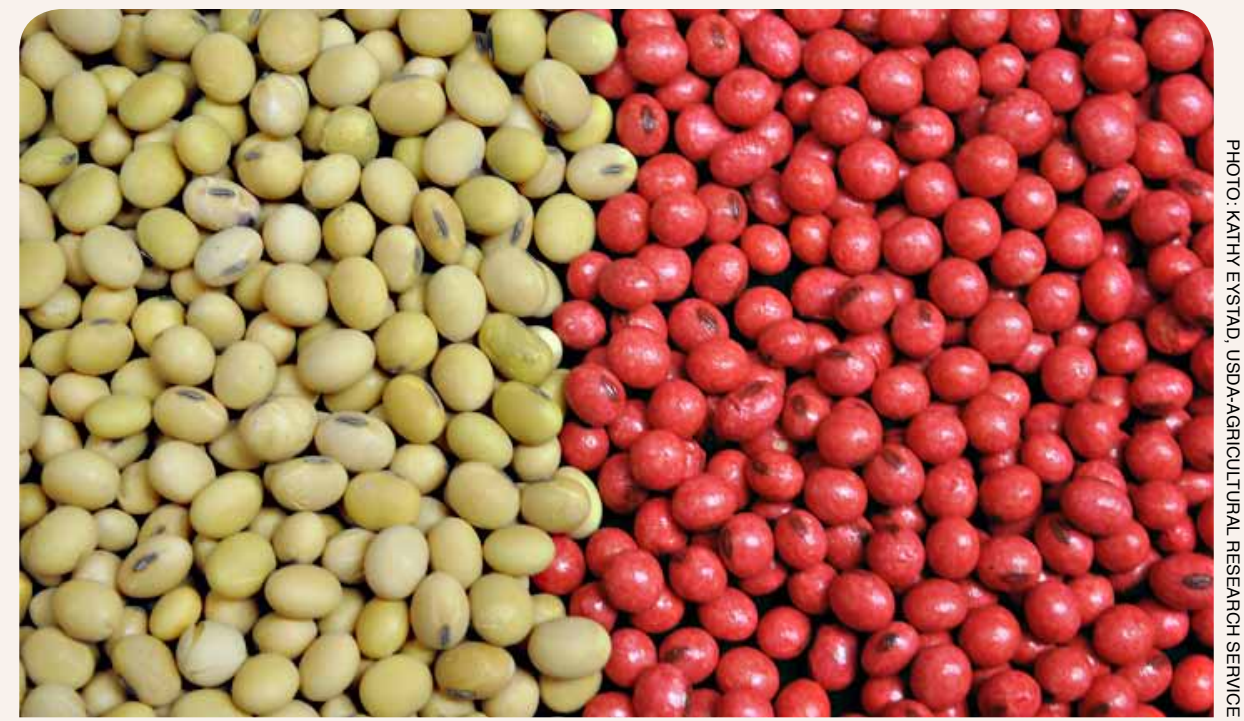

Seed companies using Roundup Ready@ technology may consider federal legal protections such as contracts and provisions of the Plant Variety Protection Act to restrict producers from saving seed.

options regarding seed saving. If the contract does not limit the right, then the producer will still want to consider if federal laws impose other limitations.

\section{PVPA Contains a Saved Seed Exemption}

Congress passed the PVPA in 1970 and amended it in 1994 to provide "patent-like" protections for sexually reproducing plants (McEowen, 2011). Developers of novel sexually reproducing plants (plants that reproduce by seed) can obtain a certificate from USDA's Agricultural Marketing Service's Plant Variety Protection Office that makes it unlawful to grow or sell protected seed varieties without the certificate holders' permission (McEowen, 2011). This protection can exist for up to 20 years. How the protection is enforced depends upon which of two options the certificate holder chooses.

Under the first option, a certificate holder can elect to sell certified or non-certified seed, granting third parties the right to use the variety for a fee or for free. Violators of PVPA certification will only be prosecuted under actions initiated by the certificate holder, not by a state or the federal government.

The second and most commonly used option, called "certificate only," allows for federal and state prosecution of violators of a certificate. Under the Federal Seed Act, violators can be fined up to $\$ 2,000$. Under Maryland's Seed Act, fines can range from $\$ 100$ to $\$ 500$ depending on the number of violations.

The PVPA has a "saved seed" exception allowing a farmer to save enough seed to plant the next crop. The saved seed exception is limited to the amount of seed needed to replant an area no bigger than that planted during the year the seed was saved (7 U.S.C. § 2543). For example, if Stan originally planted 250 acres with a PVPA- 
protected soybean variety, he could save enough of the harvested seed of that variety to plant up to 250 acres the subsequent year without violating the PVPA. If Stan plants more than 250 acres with the protected variety, he would be in violation of the PVPA. Check the seeding rates for the variety to determine how much seed may be saved.

The PVPA limits potential markets for saved seed. Section 2543 allows saved seed to be sold through all channels, with one exception: if the seller knows the seed will be used for planting a crop. For example, a large dairy determines that your PVPA protected corn seed is perfect to be milled into their feed ratio. You sell that stored corn to the dairy for use in the feed. This would not violate the PVPA. Previous court cases provide examples of selling seed illegally:

1) Sale of a standing crop for the buyer to save the seed;

2) Brown bag sales (selling seed in unmarked brown bags);

3) Bin-run sales (seller knows seed will be used for planting a crop);

4) Sale of seed as "feed," but knowing the buyer will use it for planting a crop;

5) Trading seed; and

6) Gifting seed.

As these examples show, courts have not looked kindly upon creative ways around the limitations on selling seed for planting a subsequent crop.

How do seed companies catch farmers selling uncertified PVPAprotected varieties for planting? Many of the cases involve the farmer running classified ads in local, state-

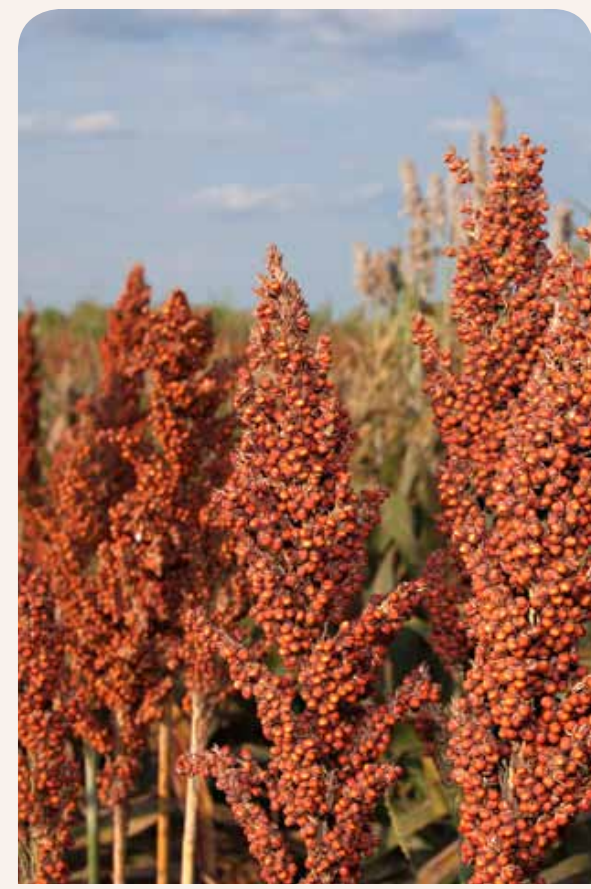

PHOTO: PEGGY GREB, USDA-AGRICULTURAL RESEARCH SERVICE

The Plant Variety Protection Act has a "saved seed" exception allowing a farmer to save enough seed to plant the next crop but is limited to the amount of seed needed to replant an area no bigger than that planted during the year the seed was saved.

wide, or multi-state agricultural newspapers, selling a certain seed variety. Seed companies or their attorneys learn of these ads and may send investigators in to purchase seed from the farmer. Neighbors also may turn a farmer in to the seed company for selling saved seed. While there are other ways a farmer could get caught trying to sell non-certified PVPA protected seeds for crop planting purposes, these are some of the most common.

Typically, buyers and sellers are liable for violations of the PVPA when seed is sold for crop planting purposes. Each could be punished with fines of up to $\$ 2,000$ per violation under the Federal Seed Act and from $\$ 100$ to $\$ 500$ depending on the number of violations under the Maryland Seed Act. For the seller, each transaction would be considered a violation of the PVPA, and violations can add up quickly if the farmer sells PVPA-protected seed to a large number of farmers.

The seed conditioning company could also be in violation of the PVPA if the staff knows a protected variety is being cleaned and was purchased via an illegal sale. For example, Charlie buys a PVPAprotected variety from Sally, his neighbor. After picking up the seed, Charlie hauls it to Bill's to be cleaned. While talking with Bill, Charlie mentions the variety's name and that he bought it from Sally. Bill knows Sally is not a certified seed dealer. Bill also has enough experience in the industry to know the variety is protected under the PVPA. If Bill knowingly cleans the seed, he also might be found in violation of the PVPA.

\section{No Patent Law Exception}

The final area of law to consider if seed will be savable is patent law. The federal government grants an inventor a patent to exclusively make, sell, and use an invention for 20 years. Life (a living product) has been patentable since 1980 when the U.S. Supreme Court ruled genetically engineered microorganisms could be patented if it met federal patent law qualifications (McEowen, 2011). Many of the commercial seed varieties sold on the U.S. market, such as any of Monsanto's Roundup Ready varieties, are protected by a patent. A developer can choose federal patent law or the PVPA to protect the new seed variety (McEowen, 2011).

Unlike the PVPA, federal patent law contains a no-seed-saved 


\section{References}

McEowen, Roger A. Expiration of Biotech Crop Patents - Issues for Growers. Ames, IA: Iowa State University Center for Agricultural Law and Taxation, April, 2011. Internet site: http://www.calt.iastate.edu/article/expiring-biotechpatents-implications-farmers

Plant Variety Protection Act of 1970, 7 U.S.C. $\S \S 2321-2582$.

35 U.S.C. $§ 284$ (2012).
Authored by:

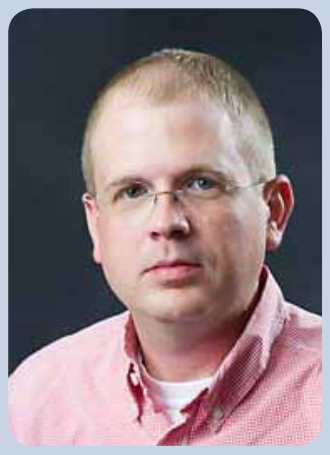

Paul Goeringer Extension Legal Specialist
The Agriculture Law Education Initiative is a collaboration between the University of Maryland Francis King Carey School and College of Agriculture \& Natural Resources, University of Maryland, College Park. Through the University of Maryland Extension - the statewide, non-formal agriculture education system the collaboration partners with the School of Agricultural and Natural Sciences, University of Maryland Eastern Shore.

The University of Maryland: MPowering the State brings together two universities of distinction to form a new collaborative partnership. Harnessing the resources of each, the University of Maryland, College Park and the University of Maryland, Baltimore will focus the collective expertise on critical statewide issues of public health, biomedical informatics, and bioengineering. This collaboration will drive an even greater impact on the state, its economy, the job market, and the next generation of innovators. The joint initiatives will have a profound effect on productivity, the economy, and the very fabric of higher education.

\section{http://www.mpowermaryland.com}

The University of Maryland programs are open to all and will not discriminate against anyone because of race, age, sex, color, sexual orientation, physical or mental disability, religion, ancestry, or national origin, marital status, genetic information, or political affiliation, or gender identity and expression.
University of Maryland College of Agriculture and Natural Resources

Department of Agricultural and Resource Economics Symons Hall, Room 2119 College Park, MD 20742 www.umaglaw.org Twitter @MDAgLaw (301) 405-1293 